IIIIIIIIIIIIIIIIIIIIIIIIIIIIIIIIIIII

Original Article

IIIIIIIIIIIIIIIIIIIIIIIIIIIIIIIIIII

\title{
Studies of factors influencing the disintegration performance of pesticide water dispersible granules
}

\author{
Shuang-yuan Cheng, Ze-quan LiU and Qiang ZHANG* \\ School of Chemistry, Beijing Institute of Technology, Beijing100081, China
}

(Received April 15, 2015; Accepted July 9, 2015)

\begin{abstract}
Disintegration property is an important parameter for evaluating the performance of pesticide water dispersible granules (WDGs). The purpose of this study is to explore the effects of pore size and pore-size distribution formed during granulation and the drying process on the disintegration property of WDGs. It was found that the pore sizes of $10 \%$ difenoconazole WDGs, prepared by adding $\mathrm{NH}_{4} \mathrm{HCO}_{3}$ as the pore-forming agent, were mostly within $4-25 \mu \mathrm{m}$. Among different drying methods, the vacuum-drying technique was responsible for a bigger capillary porosity, due to the more rapid evaporation of water. Larger pore sizes of WDGs prepared with a stronger hydrophobic polycarboxylate dispersant were obtained, as the water evaporation rate increased with increased hydrophobicity of WDGs during the drying process. The disintegration results of WDGs confirmed that a larger pore size was advantageous to the disintegration. Thus, we suggest that pore size is the key factor that significantly influences WDG disintegration performance. 우 Pesticide Science Society of Japan

Keywords: disintegration, pesticide, water dispersible granule (WDG), pore size.
\end{abstract}

\section{Introduction}

Water dispersible granules (WDGs) were a new pesticide formulation product developed in the 1980 s that require no organic solvents for preparation and application and avoid environmental pollution. ${ }^{1)}$ WDGs can be rapidly disintegrated and readily dispersed in water to form fine suspensions in the spray tank and require only gentle agitation to maintain a uniform mixture. The particle size of WDGs suspended in water is in the range of $1-10 \mu \mathrm{m}^{2)}$

Disintegration is frequently a prerequisite for the dispersion of WDGs in water and also an important index for evaluating the performance of WDGs. At present, study of WDG disintegration is focused on optimizing the WDG pesticide formula to improve its disintegration properties, ${ }^{3-7)}$ such as the effect of different disintegrants, the effect of different dispersants and fillings, and the optimizing of the preparation process. ${ }^{8)}$ However, until now, there have been few reports on the factors influencing the disintegration performance of WDGs. Bell ${ }^{1)}$ investigated four kinds of WDG examples prepared with different bonding strengths and porosities, and the results indicated that WDG strength and dispersion properties were determined by the structure of the WDGs and the bonding force among the primary particles of WDGs. WDGs with weak bonding proved to

\footnotetext{
* To whom correspondence should be addressed.

E-mail: zhangqiang6299@bit.edu.cn

Published online October 27, 2015

(c) Pesticide Science Society of Japan
}

facilitate rapid disintegration and dispersion. Delli Colli et al. ${ }^{10)}$ constructed the function relationship between the dispersant molecular weight, voidage, and the surfactant inclusion rate of WDGs; they also proposed that the most important factors influencing disintegration were the porosity and the package rate of the surfactant on the pesticide particles' surface. There is still no comprehensive and systematic theory for the WDG disintegration mechanism, and researchers mainly depend on their experience to improve the disintegration property, which restricts the development of a high-performance WDG pesticide.

Water wetting the surface and diffusing to the inner space of WDGs have been identified as steps necessary in any disintegration process, so an appropriate porosity is essential for WDGs to achieve sufficient disintegration. Ammonium bicarbonate $\left(\mathrm{NH}_{4} \mathrm{HCO}_{3}\right)$ has attracted considerate attention for use as a pore-forming material because it can be decomposed above approximately $36^{\circ} \mathrm{C}$ into $\mathrm{NH}_{3}, \mathrm{CO}_{2}$, and $\mathrm{H}_{2} \mathrm{O}$ during the drying procedure. ${ }^{11)}$ It was extensively used as a pore-forming agent in the preparation of biodegradable metallic materials, ${ }^{12,13)}$ macroporous carbon materials, ${ }^{14)}$ and so on. To investigate the relationship between pore size and the disintegration property, ammonium bicarbonate was added to WDG formulations. As one of the most important WDG additives, polymeric dispersants are well known for their wide use in the formulation pesticides for the purpose of maintaining good dispersion and stable suspension for WDG particles in water systems. It has been discovered that the hydrophilic/hydrophobic characteristic greatly influences the pore size distribution of ceramics ${ }^{15)}$ and aerogels. ${ }^{16)}$ However, the effects of the hydrophilic or hydrophobic strength 


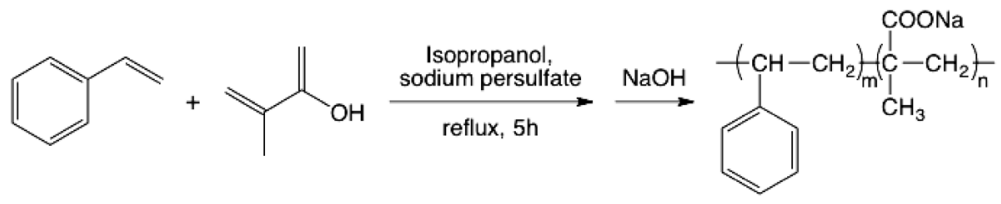

Fig. 1. The synthetic route of SSMA.

Table 1. Ingredients of WDG

\begin{tabular}{|c|c|c|c|}
\hline \multirow{2}{*}{ Components $^{\mathrm{a})}(\%)$} & \multirow{2}{*}{$\begin{array}{c}\text { I } \\
\text { Before/After drying }\end{array}$} & \multicolumn{2}{|c|}{ II } \\
\hline & & Before drying & After drying \\
\hline Difenoconazole & $10 \%$ & $10 \%$ & $10 \%$ \\
\hline Agrlian 700 & $4 \%$ & $4 \%$ & $4 \%$ \\
\hline Morwet D-425 & $3 \%$ & $3 \%$ & $3 \%$ \\
\hline AOS & $3 \%$ & $3 \%$ & $3 \%$ \\
\hline Corn Starch & $30 \%$ & $30 \%$ & $30 \%$ \\
\hline Light calcium carbonate & $12 \%$ & $12 \%$ & $12 \%$ \\
\hline Precipitated silica & $4 \%$ & $4 \%$ & $4 \%$ \\
\hline $\mathrm{NH}_{4} \mathrm{HCO}_{3}$ & $0 \%$ & $20 \%$ & $18.4 \%, 15.6 \%, 11.6 \%^{\mathrm{b})}$ \\
\hline$\left(\mathrm{NH}_{4}\right)_{2} \mathrm{SO}_{4}$ & $34 \%$ & $15.6 \%, 18.4 \%, 22.4 \%$ & $15.6 \%, 18.4 \%, 22.4 \%^{\mathrm{b})}$ \\
\hline \multicolumn{4}{|l|}{$\mathrm{B}$} \\
\hline \multirow{2}{*}{ Components ${ }^{\mathrm{a})}(\%)$} & III & \multicolumn{2}{|c|}{ IV } \\
\hline & Before/After drying & Before drying & After drying \\
\hline Emamectin Benzoate & $5 \%$ & $5 \%$ & $5 \%$ \\
\hline Agrlian 700 & $4 \%$ & $4 \%$ & $4 \%$ \\
\hline Morwet D-425 & $3 \%$ & $3 \%$ & $3 \%$ \\
\hline AOS & $3 \%$ & $3 \%$ & $3 \%$ \\
\hline Corn Starch & $30 \%$ & $30 \%$ & $30 \%$ \\
\hline Light calcium carbonate & $12 \%$ & $12 \%$ & $12 \%$ \\
\hline Precipitated silica & $4 \%$ & $4 \%$ & $4 \%$ \\
\hline $\mathrm{NH}_{4} \mathrm{HCO}_{3}$ & $0 \%$ & $20 \%$ & $18.4 \%, 15.6 \%, 11.6 \%, 8.8 \%, 8.4 \%, 0.8 \%^{\mathrm{b})}$ \\
\hline$\left(\mathrm{NH}_{4}\right)_{2} \mathrm{SO}_{4}$ & $34 \%$ & $15.6 \%, 18.4 \%, 22.4 \%, 25.2 \%, 25.6 \%, 33.2 \%$ & $15.6 \%, 18.4 \%, 22.4 \%, 25.2 \%, 25.6 \%, 33.2 \%{ }^{\mathrm{b}}$ \\
\hline \multicolumn{4}{|l|}{$\mathrm{C}$} \\
\hline Components $^{\mathrm{a})}(\%)$ & $\mathrm{V}$ & & \\
\hline Difenoconazole & $10 \%$ & & \\
\hline SSMA & $7 \%$ & & \\
\hline AOS & $3 \%$ & & \\
\hline Corn Starch & $30 \%$ & & \\
\hline Light calcium carbonate & $12 \%$ & & \\
\hline Precipitated silica & $4 \%$ & & \\
\hline$\left(\mathrm{NH}_{4}\right)_{2} \mathrm{SO}_{4}$ & Make up to $100 \%$ & & \\
\hline
\end{tabular}

a) Agrlian 700, Polycarboxylate dispersant (Akzo Nobel N.V, Holland); Morwet D-425, Sodium alkyl naphthalene sulfonic acid polycondensate salt (Akzo Nobel N.V, Holland); AOS, Sodium alpha-olefin sulfonate (Carnier Technology Co., Ltd., Nanjing, China) (90\% purity); Corn Starch (99.9\% purity, Qing An Chemistry Co., Ltd., Shandong, China); Light calcium carbonate (98\% purity, Bai Ruide Trading Company, Tianjing, China); Precipitated silica

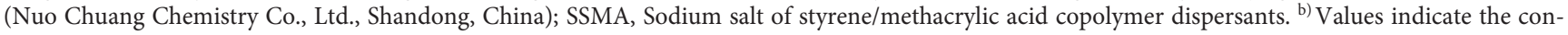
tents after drying at different temperature. See text.

of anionic polymeric dispersants on the WDG's pore structure and disintegration have not been reported.

To investigate the relationship between pore size and disin- tegration of WDGs, the influence of adding ammonium bicarbonate, vacuum-drying, ${ }^{17)}$ or using polycarboxylate dispersants with the different ratios of the hydrophilic to hydrophobic group 

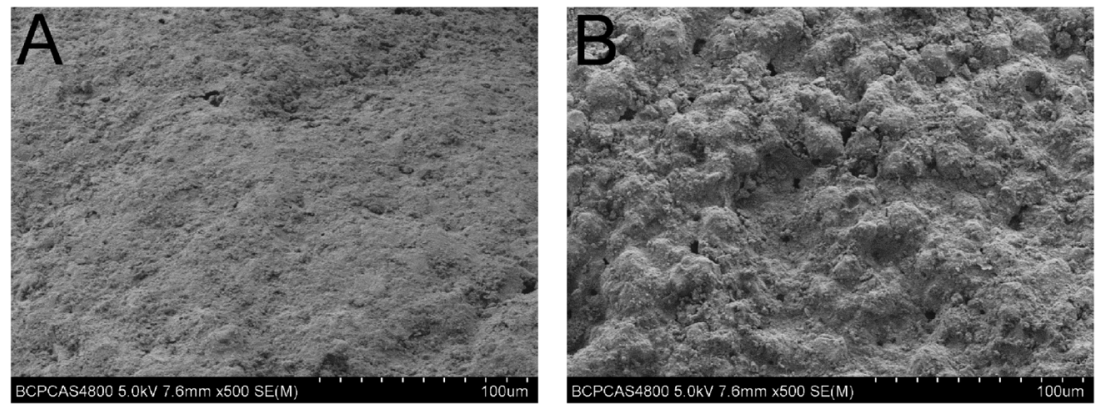

Fig. 2. SEM images of $10 \%$ difenoconazole WDGs dried under atmospheric pressure at $50^{\circ} \mathrm{C}(\mathrm{A})$ in the absence of $\mathrm{NH}_{4} \mathrm{HCO}_{3}$ and $(\mathrm{B})$ in the presence of $20 \mathrm{wt} \% \mathrm{NH}_{4} \mathrm{HCO}_{3}$.
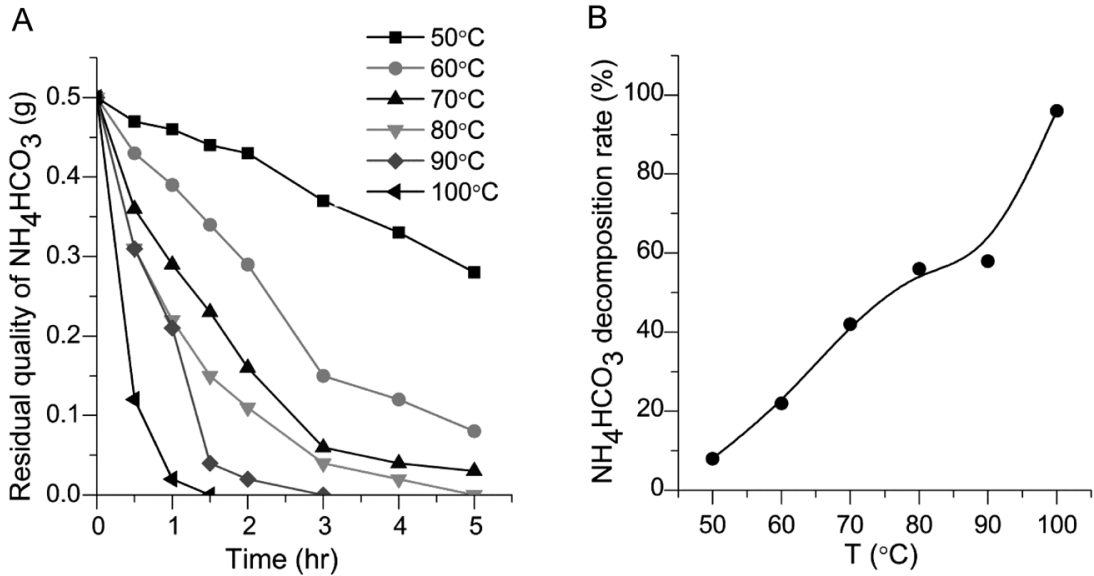

Fig. 3. Temperature dependency on $\mathrm{NH}_{4} \mathrm{HCO}_{3}$ decomposition. (A) Residual quantity of $\mathrm{NH}_{4} \mathrm{HCO}_{3}$ against the time by drying under atmospheric pressure. (B) Temperature dependency on $\mathrm{NH}_{4} \mathrm{HCO}_{3}$ decomposition rate (1 hr of drying).

on the WDG pore structure was studied, and the disintegration mechanisms of WDGs in water systems were also discussed.

\section{Materials and Methods}

\section{Materials}

Difenoconazole (Dongtai Agrochemical Chemistry Co., Ltd., Shandong, China) (melting point: $82-83^{\circ} \mathrm{C}$ ) (95\% purity); Emamectin Benzoate (JUMBO BIOCHEM Co., Ltd., Chifeng, China) (melting point: $\left.141-146^{\circ} \mathrm{C}\right)(97 \%$ purity).

Sodium salt of styrene/methacrylic acid copolymer dispersants (SSMA) were synthesized at different molar ratios of styrene and methacrylic acid $(\mathrm{m}: \mathrm{n}=1: 2,1: 3,1: 4,1: 10)$, with a $3.0 \%$ initiator and reacting at $80^{\circ} \mathrm{C}$ for $5 \mathrm{hr}$, according to Fig. 1 . Then the SSMA were obtained by spray drying the liquid products.

\section{Preparation of WDGs}

Ten percent difenoconazole WDGs and 5\% emamectin benzoate WDGs were prepared with the formula shown in Table 1. The mixture of pesticide, dispersant, wetting agent, and other additives crushed by air comminuting was first blended with a highshear mixer, and then granulated with an appropriate amount of water as a binder solution in a ZLB-80 rotating granulator. The prepared WDGs were then dried at different temperatures and with different techniques. For drying under atmospheric pressure, when the content of $\mathrm{NH}_{4} \mathrm{HCO}_{3}$ was $20 \%$, the contents of $\left(\mathrm{NH}_{4}\right)_{2} \mathrm{SO}_{4}$ were $15.6 \%, 18.4 \%, 22.4 \%, 25.2 \%, 25.6 \%$, and $33.2 \%$ for drying at $50,60,70,80,90$ and $100^{\circ} \mathrm{C}$ respectively (Table $1 \mathrm{II}$, IV). Then the samples were placed in ventilated ovens and regulated at $50^{\circ} \mathrm{C}, 60^{\circ} \mathrm{C}, 70^{\circ} \mathrm{C}, 80^{\circ} \mathrm{C}, 90^{\circ} \mathrm{C}$ or $100^{\circ} \mathrm{C}$ for $1 \mathrm{hr}$. However, for vacuum-drying tests, $10 \%$ difenoconazole WDGs and $5 \%$ emamectin benzoate WDGs without the addition of $\mathrm{NH}_{4} \mathrm{HCO}_{3}$ (Table 1 I, III) were dried in a vacuum device that allowed the application of a vacuum of about $0.001 \mathrm{MPa}$ regulated at $50^{\circ} \mathrm{C}$ for $1 \mathrm{hr}$. SSMA with different hydrophilic-to-hydrophobic group ratios $(\mathrm{m}: \mathrm{n}=1: 2,1: 3,1: 4,1: 10)$ were applied to the $10 \%$ difenoconazole WDG formulation (Table $1 \mathrm{~V}$ ) of prepared WDGs by drying at $50^{\circ} \mathrm{C}$ under atmospheric pressure for $1 \mathrm{hr}$. After drying, the water contents of WDGs were less than $2 \%$. Ten percent difenoconazole WDGs and 5\% emamectin benzoate WDGs were prepared under different conditions, after drying, with a diameter of $1.0 \mathrm{~mm}$ and a length of approximately $6.0 \mathrm{~mm}$. No breakage of granules was observed after drying.

\section{Disintegration of WDGs}

We quickly poured $0.5 \mathrm{~g}$ of WDGs into $90 \mathrm{~mL}$ of deionized water 
in a $100-\mathrm{mL}$ cylinder with a stopper at $25^{\circ} \mathrm{C}$, and it was rotated around the middle of the cylinder at a speed of $8 \mathrm{rev} / \mathrm{min}$. The rotation times it took WDGs to completely disintegrate in water are called the disintegration times.

\section{Morphology of WDGs}

Scanning electron microscopy (SEM) was used to investigate the morphology of WDGs. The samples were observed in a Hitachi S-4800N SEM (Hitachi Ltd., Japan).

\section{Characterization of pore-size distributions}

The pore-size distributions of the samples were determined using a PoreMaster GT60 mercury intrusion porosimetry (MIP) (Quantachrome Instruments, Boynton Beach, FL, USA). The diameter of pores was calculated according to the Washburn equation, ${ }^{18)}$ as shown in Eq. (1):

$$
D=-4 \gamma \cos \theta / p
$$

where $D$ is the pore diameter $(\mu \mathrm{m}), \gamma$ is the surface tension of mercury $(\mathrm{mN} / \mathrm{m}), \theta$ is the contact angle between mercury and the WDG, and $p$ is the applied pressure $(\mathrm{MPa})$. The surface tension of mercury applied here was $480 \mathrm{mN} / \mathrm{m}$ while the contact angle between mercury and the WDG used was $140^{\circ}$. The pressure used varied between $0.0146 \mathrm{MPa}$ and $14.6 \mathrm{MPa}$, approximately corresponding to pore diameter sizes of approximately 100 and $0.1 \mu \mathrm{m}$, respectively.

\section{Particle hardness of WDGs}

Radial crushing strength was used as a measure for the particle hardness of WDGs. Radial crushing strengths of WDGs were tested with a ZQJ-II digital particle strength tester (Digital Testing Machineries Factory, Dalian, China), and the average valve was recorded.

\section{Results and Discussion}

1. Morphology of $10 \%$ difenoconazole WDGs

To study the relationship between pore size distribution and disintegration of WDGs, ammonium bicarbonate was added as a pore-forming agent that can be decomposed at low temperatures. ${ }^{13)}$ SEM images of the $10 \%$ difenoconazole WDGs dried at $50^{\circ} \mathrm{C}$ are shown in Fig. 2. A relatively smooth surface and micropores were observed for WDGs without $\mathrm{NH}_{4} \mathrm{HCO}_{3}$ (Fig. 2A); however, the surface of WDGs filled with $\mathrm{NH}_{4} \mathrm{HCO}_{3}$ was uneven and had many mesoporous around $10 \mu \mathrm{m}$ in size, as shown in Fig. 2B. It was suggested that the micropores in Fig. 2A originated from the slow evaporation of water in WDGs during the drying process, while the mesopores in Fig. $2 \mathrm{~B}$ were induced by the fast diffusion of $\mathrm{CO}_{2}$ and $\mathrm{NH}_{3}$ decomposed from $\mathrm{NH}_{4} \mathrm{HCO}_{3}$ during the drying process.

\section{Pore-size distribution and the disintegration property \\ 2.1. Effect of $\mathrm{NH}_{4} \mathrm{HCO}_{3}$}

Temperature dependencies on $\mathrm{NH}_{4} \mathrm{HCO}_{3}$ decomposition reaction curves are shown in Fig. $3 \mathrm{~A}$ and $\mathrm{B} . \mathrm{NH}_{4} \mathrm{HCO}_{3}$ decom-
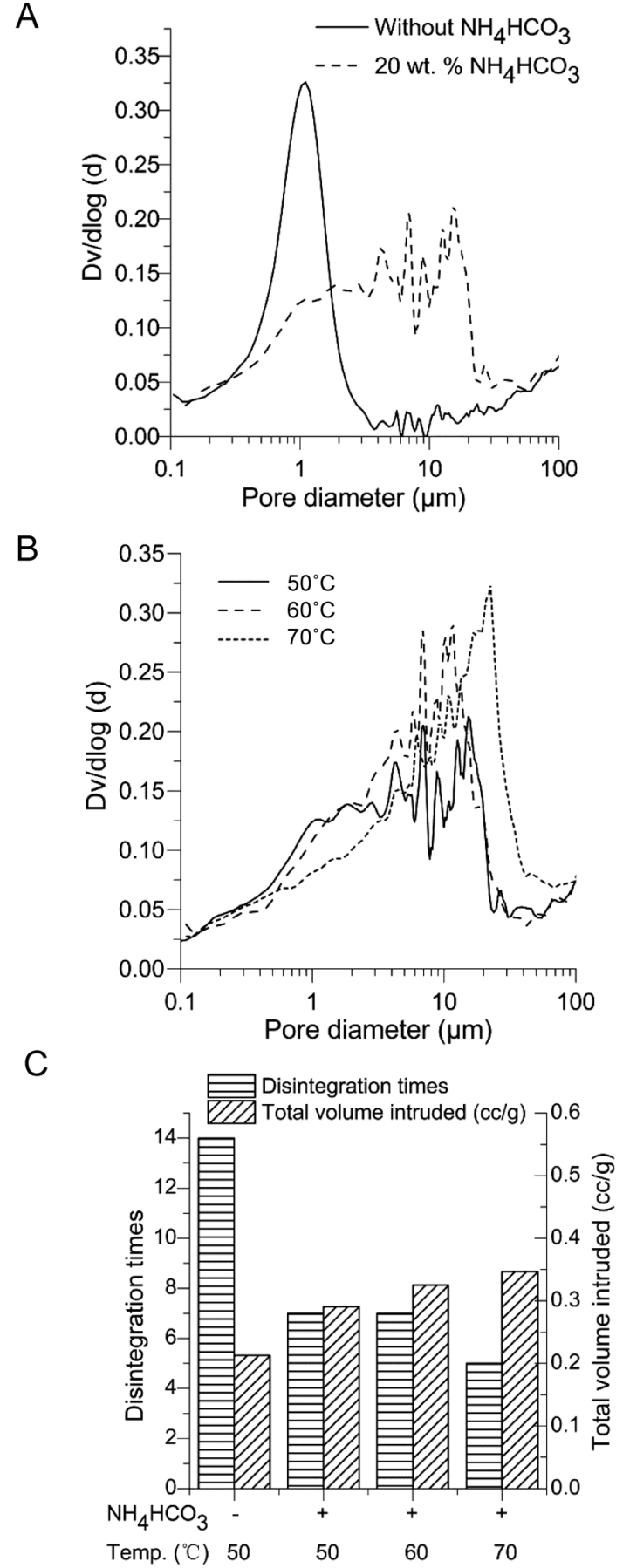

Fig. 4. Ten percent difenoconazole WDGs dried under atmospheric pressure. (A) Pore-size distribution determined by means of MIP for WDGs dried without $\mathrm{NH}_{4} \mathrm{HCO}_{3}$ and with $20 \mathrm{wt} \% \mathrm{NH}_{4} \mathrm{HCO}_{3}$ at $50^{\circ} \mathrm{C}$ for $1 \mathrm{hr}$. (B) Pore-size distribution of WDGs with $20 \mathrm{wt} \% \mathrm{NH}_{4} \mathrm{HCO}_{3}$ dried at 50, 60 and $70^{\circ} \mathrm{C}$ for $1 \mathrm{hr}$. (C) Disintegration times and the total volumes of mercury intrusion $(\mathrm{cc} / \mathrm{g})$ of WDGs without $\mathrm{NH}_{4} \mathrm{HCO}_{3}$ dried at $50^{\circ} \mathrm{C}$ and filled with $20 \mathrm{wt} \% \mathrm{NH}_{4} \mathrm{HCO}_{3}$ dried at 50,60 and $70^{\circ} \mathrm{C}$.

position rates under different temperatures can be obtained, as shown in Fig. $3 \mathrm{~B}$, so that when $20 \% \mathrm{NH}_{4} \mathrm{HCO}_{3}$ content was added to the pesticide formulations, the $\left(\mathrm{NH}_{4}\right)_{2} \mathrm{SO}_{4}$ contents were $15.6 \%, 18.4 \%, 22.4 \%, 25.2 \%, 25.6 \%$, and $33.2 \%$ for 50,60 , 
Table 2. Radial crushing strength of $10 \%$ Difenoconazole WDG

\begin{tabular}{lc}
\hline Samples $^{\mathrm{a})}$ & Radial Crushing Strength $(\mathrm{N} / \mathrm{mm})$ \\
\hline DAS50 & 5.40 \\
DNAS50 & 5.67 \\
DNAS70 & 5.66 \\
\hline
\end{tabular}

a) $\mathrm{D}, 10 \%$ Difenoconazole WDG; $\mathrm{N}$, with $20 \% \mathrm{NH}_{4} \mathrm{HCO}_{3}$; A, drying under atmospheric pressure. Numerical value shows drying temperature; S, samples.

70, 80, 90 and $100^{\circ} \mathrm{C}$ (Table $1 \mathrm{II}, \mathrm{IV}$ ). After drying at different temperatures, the sum of the $\mathrm{NH}_{4} \mathrm{HCO}_{3}$ and $\left(\mathrm{NH}_{4}\right)_{2} \mathrm{SO}_{4}$ contents was the same as the $34 \%$ content of $\left(\mathrm{NH}_{4}\right)_{2} \mathrm{SO}_{4}$ (Table $1 \mathrm{I}$ ).

Figure $4 \mathrm{~A}$ shows the pore-size distribution of $10 \%$ difenoconazole WDGs as measured by MIP. It can be found that WDGs in the absence of $\mathrm{NH}_{4} \mathrm{HCO}_{3}$ have unimodal pore-size distributions in the range of $0.2-2 \mu \mathrm{m}$ (Fig. $4 \mathrm{~A}$ ), while WDGs filled with $20 \mathrm{wt} \%$ of $\mathrm{NH}_{4} \mathrm{HCO}_{3}$ have multimodal pore-size distributions in the range of $1-20 \mu \mathrm{m}$ with a mode pore diameter of $7.05 \mu \mathrm{m}$ (Fig. 4A). Figure 4B shows the pore-size distributions of WDGs filled with $20 \mathrm{wt} \%$ of $\mathrm{NH}_{4} \mathrm{HCO}_{3}$ dried at different temperatures. It was observed that the pore sizes of samples dried at $50^{\circ} \mathrm{C}$ or $60^{\circ} \mathrm{C}$ were mainly $1-20 \mu \mathrm{m}$, while the pore sizes of samples dried at $70^{\circ} \mathrm{C}$ increased into the range of $3-30 \mu \mathrm{m}$ with a mode pore diameter of approximately $20 \mu \mathrm{m}$. Moreover, pore sizes measured by MIP correspond to the pore sizes observed by SEM. With the addition of $\mathrm{NH}_{4} \mathrm{HCO}_{3}$, disintegration times decreased from 14 to 7 (Fig. 4C), which might suggest that capillary pores in the range of $2-20 \mu \mathrm{m}$ were very conducive to the diffusion of water in the channels of WDGs and were advantageous to the disintegration of WDGs.

Obviously, as the temperature increased, pore sizes became larger, and the amount of larger pores increased due to more $\mathrm{NH}_{4} \mathrm{HCO}_{3}$ decomposition, as shown in Fig. 3. The maximum peaks also shift to higher values. ${ }^{19)}$ The maximum peak dried at $50^{\circ} \mathrm{C}$ was approximately $15 \mu \mathrm{m}$, whereas the maximum peak dried at $70^{\circ} \mathrm{C}$ reached $25 \mu \mathrm{m}$ (Fig. $4 \mathrm{~B}$ ). The total volume of mercury intrusion increased from 0.2126 to $0.3466 \mathrm{cc} / \mathrm{g}$, and the disintegration times decreased to 5 (Fig. 4C). However, except for pore size and particle size, the hardness of WDGs may also influence their disintegration performance. Table 2 shows the radial crushing strength of $10 \%$ difenoconazole WDGs tested using a digital particle strength tester. It can be observed from Table 2 that $10 \%$ difenoconazole WDGs prepared under different conditions showed the same radial crushing strength, so we suggest that particle hardness is not the main parameter influencing the disintegration times of WDGs in our research systems. These results indicate that the larger pores are very important to the disintegration of WDGs.

The pore-size distributions of 5\% emamectin benzoate WDGs measured by MIP are shown in Fig. 5A. The 5\% emamectin benzoate WDG in the absence of $\mathrm{NH}_{4} \mathrm{HCO}_{3}$ dried at $50^{\circ} \mathrm{C}$ mainly had pore-size distributions in the range of $0.5-5 \mu \mathrm{m}$, while the sample filled with $\mathrm{NH}_{4} \mathrm{HCO}_{3}$ was in the range of $2-30 \mu \mathrm{m}$, and
A

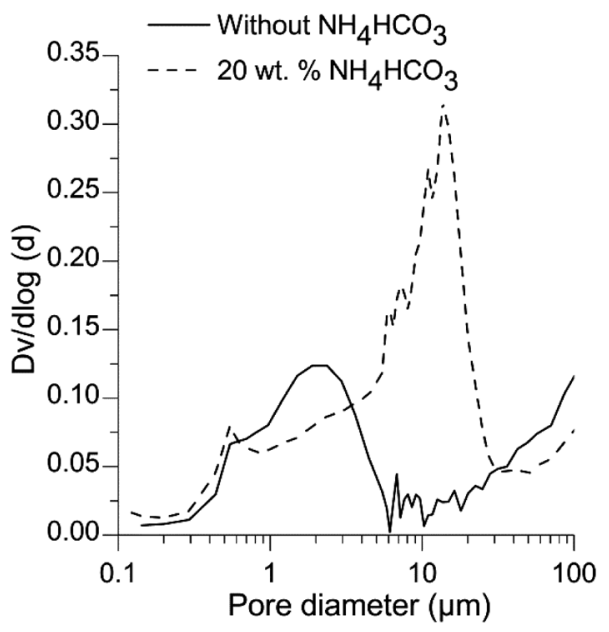

B

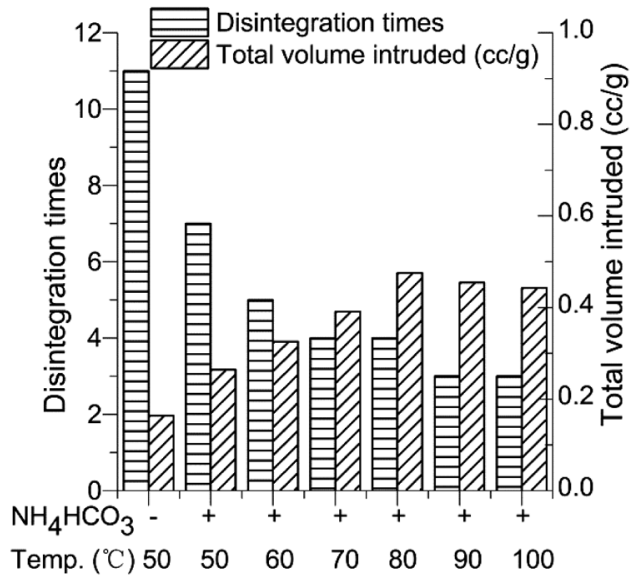

C

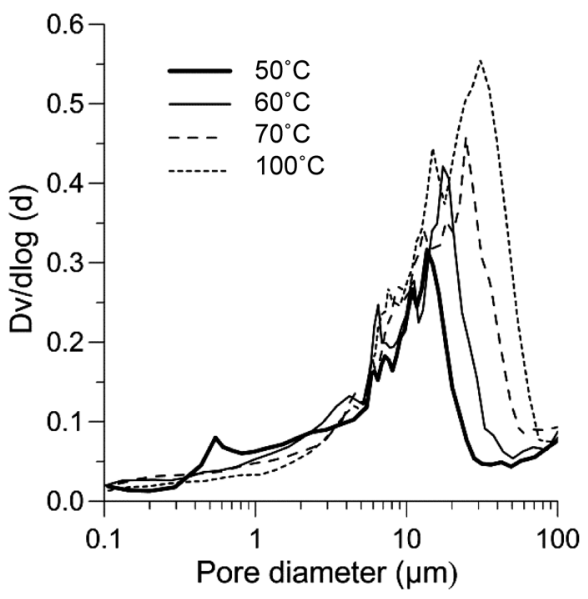

Fig. 5. Five percent emamectin benzoate WDGs dried under atmospheric pressure. (A) Pore-size distribution determined by means of MIP for WDGs dried without $\mathrm{NH}_{4} \mathrm{HCO}_{3}$ and with $20 \mathrm{wt} \% \mathrm{NH}_{4} \mathrm{HCO}_{3}$ at $50^{\circ} \mathrm{C}$ for $1 \mathrm{hr}$. (B) Disintegration times and the total volumes of mercury intrusion $(\mathrm{cc} / \mathrm{g})$ of WDGs without $\mathrm{NH}_{4} \mathrm{HCO}_{3}$ dried at $50^{\circ} \mathrm{C}$ and filled with $20 \mathrm{wt} \% \mathrm{NH}_{4} \mathrm{HCO}_{3}$ dried at 50,60, 70, 80, 90 and $100^{\circ} \mathrm{C}$. (C) Pore size distribution of WDGs with $20 \mathrm{wt} \% \mathrm{NH}_{4} \mathrm{HCO}_{3}$ dried at $50,60,70$ and $100^{\circ} \mathrm{C}$ for $1 \mathrm{hr}$. 
the peak reached a maximum at around $18 \mu \mathrm{m}$. In contrast, the total volume of mercury intrusion increased, and disintegration times decreased from 11 to 7 (Fig. 5B). Because the decomposition rate of $\mathrm{NH}_{4} \mathrm{HCO}_{3}$ increased with increasing temperature, the maximum peak also shifted to higher values. For example, the peak dried at $100^{\circ} \mathrm{C}$ was around $35 \mu \mathrm{m}$, as shown in Fig. 5C. Simultaneously, the pore-size distributions obtained at different temperatures were consistent with the disintegration times results shown in Fig. 5B. Thus, it can be concluded that a greater number of larger pores are very conducive to water diffusion in the channels of WDGs and to improving disintegration performance.

Difenoconazole and emermectin benzoate have different physical and chemical properties. To prove the general applicability and validity of the conclusions in this paper, we used different active ingredients for our experiments. The different ways in which active ingredients affected the porosity of the granules might come from the different strengths of the interactions be-

B

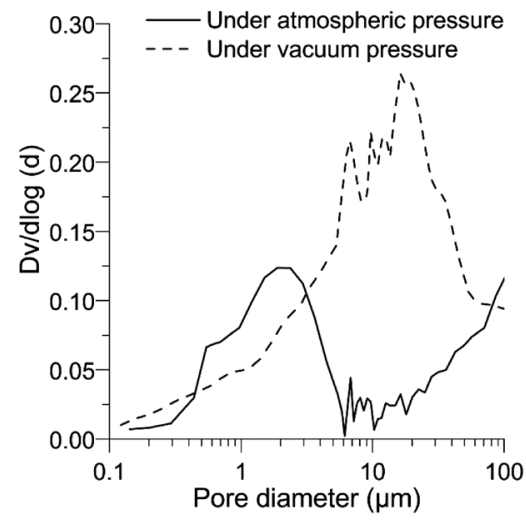

Fig. 6. The influence of drying techniques on pore-size distributions of WDGs. (A) Ten percent difenoconazole WDGs dried under atmospheric pressure and under vacuum pressure at $50^{\circ} \mathrm{C}$ for $1 \mathrm{hr}$. (B) Five percent emamectin benzoate WDGs dried under atmospheric pressure and under vacuum pressure at $50^{\circ} \mathrm{C}$ for $1 \mathrm{hr}$.

Table 3. Disintegration times and the volumes of mercury intrusion of $10 \%$ Difenoconazole WDG

\begin{tabular}{lcccc}
\hline & \multicolumn{3}{c}{ Volume Intruded $(\mathrm{cc} / \mathrm{g})$} & Disintegration times \\
\cline { 2 - 4 } Samples $^{\mathrm{a})}$ & $0.1-2 \mu \mathrm{m}$ & $2-20 \mu \mathrm{m}$ & $20-50 \mu \mathrm{m}$ & 14 \\
DAS50 & 0.1657 & 0.0197 & 0.0108 & 7 \\
DNAS50 & 0.1027 & 0.1489 & 0.0218 & 7 \\
DNAS60 & 0.0947 & 0.1917 & 0.0222 & 5 \\
DNAS70 & 0.0790 & 0.1956 & 0.0608 & 10 \\
DVS50 & 0.0663 & 0.1226 & 0.0554 & 10 \\
\hline
\end{tabular}

a) $\mathrm{V}$, drying under vacuum pressure $(0.001 \mathrm{MPa})$; Others are the same as Table 2.

Table 4. Disintegration times and the volumes of mercury intrusion of 5\% Emamectin Benzoate WDG

\begin{tabular}{|c|c|c|c|c|}
\hline \multirow{2}{*}{ Samples ${ }^{\mathrm{a})}$} & \multicolumn{3}{|c|}{ Volume Intruded (cc/g) } & \multirow{2}{*}{ Disintegration times } \\
\hline & $0.1-2 \mu \mathrm{m}$ & $2-20 \mu \mathrm{m}$ & $20-50 \mu \mathrm{m}$ & \\
\hline EBAS50 & 0.0700 & 0.0461 & 0.0213 & 11 \\
\hline EBNAS50 & 0.0608 & 0.1648 & 0.0222 & 7 \\
\hline EBNAS60 & 0.0538 & 0.2019 & 0.0509 & 5 \\
\hline EBNAS70 & 0.0538 & 0.2038 & 0.1098 & 4 \\
\hline EBNAS80 & 0.0377 & 0.2125 & 0.1824 & 4 \\
\hline EBNAS90 & 0.0366 & 0.2160 & 0.1698 & 3 \\
\hline EBNAS100 & 0.0287 & 0.1929 & 0.1657 & 3 \\
\hline EBVS50 & 0.0454 & 0.1770 & 0.0657 & 6 \\
\hline
\end{tabular}

${ }^{\text {a) }} \mathrm{EB}, 5 \%$ Emamectin Benzoate WDG; Others are the same as Table 2. 
tween active ingredient and other additives, which influenced the granulated course.

\subsection{Effect of different drying procedures}

The pore-size distributions of $10 \%$ difenoconazole WDGs without the addition of $\mathrm{NH}_{4} \mathrm{HCO}_{3}$ (Table $1 \mathrm{I}$ ) prepared by drying under atmospheric pressure and vacuum pressure are shown in Fig. 6A. It can be readily observed that the pore-size distribution prepared using the vacuum-drying technique has multimodal peaks and shifts to larger pore sizes in the range of $4-50 \mu \mathrm{m}$, as contrasted with a unimodal peak with drying under atmospheric pressure. Moreover, the disintegration time with vacuum drying is 10 , significantly lower than 14 when dried under atmospheric pressure (Table 3). It is generally believed that all drying techniques separately affect the microstructures of materials, to some extent. ${ }^{20)}$ Due to the reduction of water-saturated vapor pressure, steam could quickly escape from the inner space of WDGs during the course of vacuum drying, and some larger pores showed on the surface and interior of the samples, which was very conducive to improving the disintegration performance.

The pore-size distributions of 5\% emamectin benzoate WDGs without the addition of $\mathrm{NH}_{4} \mathrm{HCO}_{3}$ (Table $1 \mathrm{III}$ ) prepared by drying under atmospheric pressure and vacuum pressure are shown in Fig. 6B. Similar to $10 \%$ difenoconazole WDGs, the pore-size distribution peaks with vacuum-drying were also shifted to larger pore sizes, as compared to those dried under atmospheric pressure. The disintegration time with vacuum drying is 6 , far lower than 11 when dried under atmospheric pressure (Table 4). The results also confirm that the formation of larger pore structure is related to the rate of water evaporation, and that vacuum drying contributes beneficially to the formation of larger pores.

Tables 3 and 4 show the relationship between pore size and disintegration time. From Tables 3 and 4, it can be seen that disintegration times increased with the increased volume intruded in the range of $2-20 \mu \mathrm{m}$, and most of pores were in the $2-20 \mu \mathrm{m}$ range. Therefore, it can be concluded that the formation of capillary pores in the range of $2-20 \mu \mathrm{m}$ is the key factor for the improving the disintegration performance of WDGs. For example, though the total volume intruded was increased at $80^{\circ} \mathrm{C}$ from $70^{\circ} \mathrm{C}$ in Fig. $5 \mathrm{~B}$, the disintegration times were not increased. This is because there is little difference between the volume intruded at $2-20 \mu \mathrm{m}$ at $80^{\circ} \mathrm{C}$ and that at $70^{\circ} \mathrm{C}$, and the increase of lager pores $(>20 \mu \mathrm{m})$ made the total volume increase at $80^{\circ} \mathrm{C}$.

2.3. Effect of hydrophilic/hydrophobic characteristics of SSMA SSMA with different hydrophilic-to-hydrophobic group ratios $(\mathrm{m}: \mathrm{n})$ were synthesized, and $10 \%$ difenoconazole WDGs (Table $1 \mathrm{~V}$ ) using SSMA dispersants with different hydrophilic-to-hydrophobic group ratios were dried under atmospheric pressure for $1 \mathrm{hr}$. Disintegration times increased with the rise of the hydrophilic group ratio, as shown in Fig. 7A. The disintegration time was only 4 at $\mathrm{m}: \mathrm{n}=1: 2$, while the disintegration time reached 25 at $\mathrm{m}: \mathrm{n}=1: 10$ (Fig. 7A). The pore-size distributions of WDGs using SSMA dispersants with different hydrophilic-to-hydrophobic group ratios are shown in Fig. 7B.
A

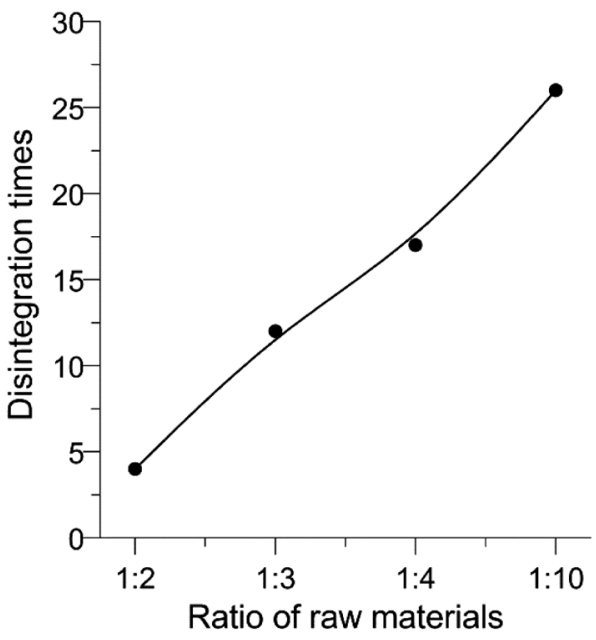

B
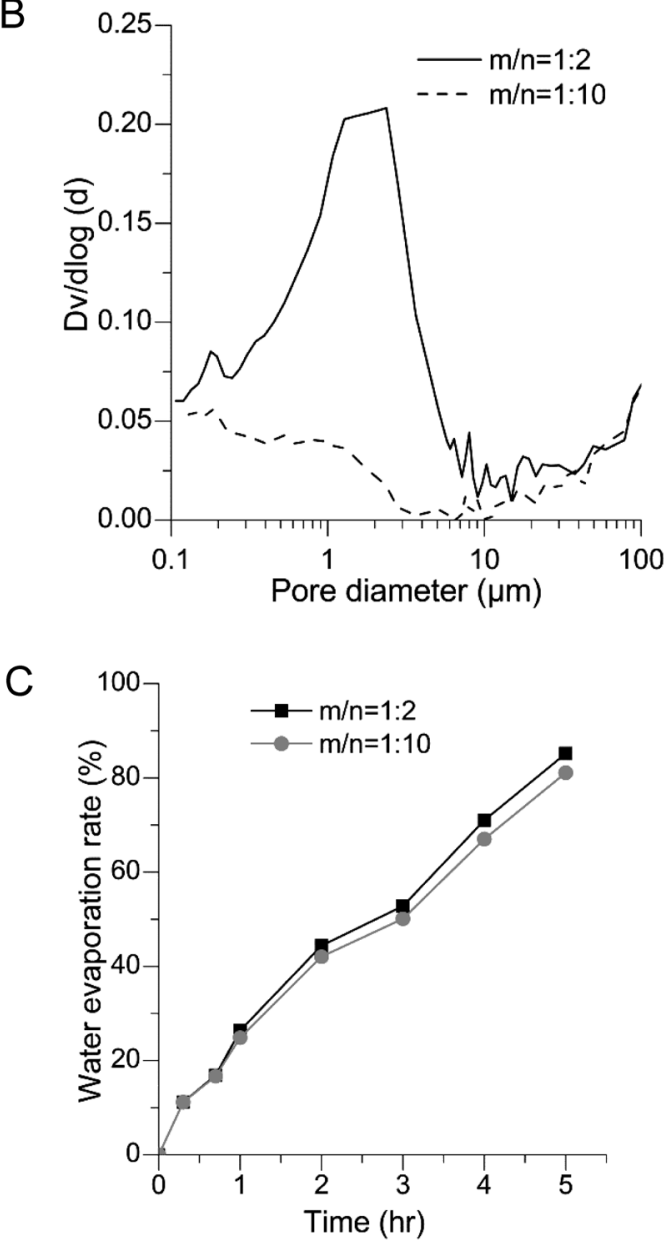

Fig. 7. Effect of hydrophilic-to-hydrophobic group ratios on the performance of WDGs. (A) Effect of hydrophilic-to-hydrophobic group ratios on WDG disintegration times. (B) Hydrophilic-to-hydrophobic group ratios of SSMA $(\mathrm{m}: \mathrm{n}=1: 2,1: 10)$ on pore-size distributions of $10 \%$ difenoconazole WDGs. (C) Water evaporation rate of a $10 \mathrm{wt} \%$ aqueous solution of SSMA ( $m: n=1: 2,1: 10)$ drying under atmospheric pressure. 


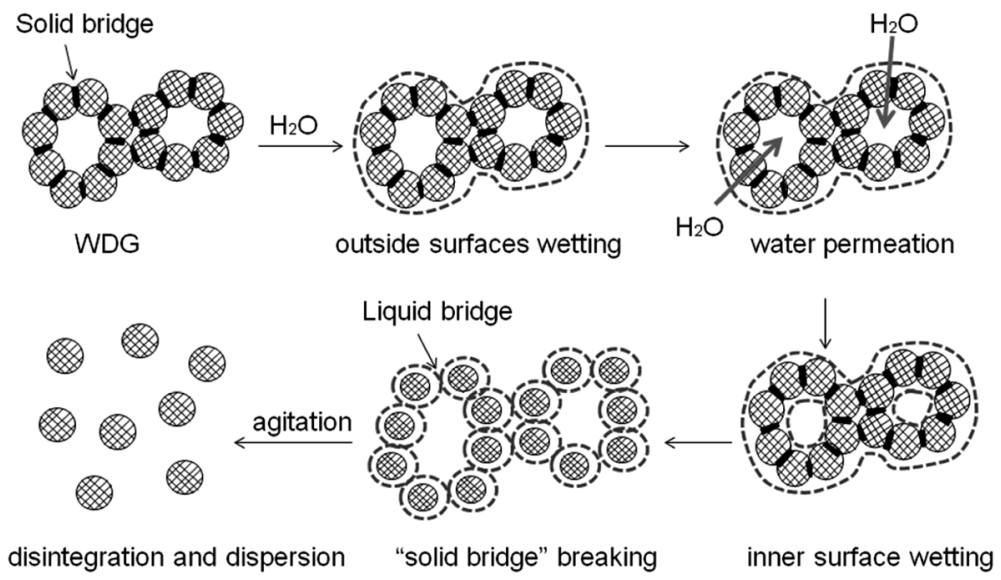

Fig. 8. Schematic diagram of disintegration mechanisms of WDGs in water systems.

It can be observed that samples prepared with stronger hydrophobic dispersants resulted in the formation of larger pore size, corresponding to fewer disintegration times. Evaporation rate of a $10 \mathrm{wt} \%$ aqueous solution of SSMA $(\mathrm{m}: \mathrm{n}=1: 2,1: 10)$ dried under atmospheric pressure at $50^{\circ} \mathrm{C}$ is shown in Fig. $7 \mathrm{C}$. It is found that an aqueous solution of dispersants with stronger hydrophobicity loses water more easily. It can be inferred that stronger hydrophilic dispersants presented stronger interactions with water during the drying process, which slowed the water evaporation and led to the formation of fine pores. However, stronger hydrophobic dispersants presented stronger repulsive forces with water during the drying process, which resulted in the formation of larger pores due to the rapid evaporation of water. The results indicate that the effects of the polymeric dispersants on disintegration times and pore-size distributions depended greatly on the hydrophilic group ratio of the dispersants and that higher hydrophobicity is conducive to improving the disintegration performance of WDGs.

\section{The disintegration mechanism of WDG}

WDGs were prepared from finely milled powders, including pesticides, dispersants, wetting agents, and other additives, which were granulated with water as a binder solution to produce free-flowing granules. ${ }^{8)}$ As previously discussed, the WDG formula, drying methods, and hydrophilic/hydrophobic characteristics of dispersants all greatly influenced pore-size distributions and further affected the disintegration property of WDGs. When WDGs were poured into water, the outside surfaces might be wetted first. Water then permeates the inner space through a channel, the inner surfaces can be wetted, and the "solid bridge" among primary particles by Van der Waals force might weaken and disappear. Subsequently, WDGs will disperse into primary particles, and the disintegration event takes place. So we suggested that the disintegration mechanism of WDGs might follow this process: outside surface wetting-water permeation-inner surface wetting-"solid bridge" breaking-disintegration-dispersion, as shown in Fig. 8.

\section{Conclusion}

Pore-size distributions of WDGs prepared under different conditions were characterized using MIP and SEM, which were compared to the corresponding disintegration times. Our research showed that the WDG formula, drying methods, and hydrophilic/hydrophobic characteristic of dispersants greatly influenced pore-size distributions and further affected the disintegration property of WDGs.

Ammonium bicarbonate, when filled in a WDG formulation as a pore-forming agent, will lead to the formation of larger pores and improve the disintegration performance of WDGs. Of different methods of drying WDGs, the vacuum-drying technique was responsible for greater capillary porosity that was conducive to WDG disintegration, due to the more rapid evaporation of water. Moreover, the characteristic of polymer dispersants was also an important parameter affecting WDG properties. The effects of the polymer dispersants on disintegration times and pore-size distributions were greatly dependent on the hydrophilic/hydrophobic characteristic of dispersants; stronger hydrophobicity was conducive to improving disintegration performance.

It is suggested that the disintegration mechanism of WDG might follow this process: outside surface wetting-water permeation-inner surface wetting-"solid bridge" breaking-disintegration-dispersion.

The formation of capillary pores in the range of $2-20 \mu \mathrm{m}$ or larger is the key factor for improving the disintegration performance of WDGs. Factors other than porosity also affect disintegration times to a certain extent, such as particle size and hardness of the granules. These results are meaningful for the development of high-performance WDG pesticides.

\section{Acknowledgements}

This work was financially supported by the National Science and Technology Pillar Program in the 12th Five Year Plan Period (No. 2011BAE06B06-2). 


\section{References}

1) S. J. Liu, Z. Li and Z. Wang: Adv. Mater. Res. 550, 873-876 (2002).

2) R. Wiwattanapatapee, A. Sae-Yun, J. Petcharat, C. Ovatlarnporn and A. Itharat: J. Agric. Food Chem. 57, 11234-11241 (2009).

3) Z. Lu, Z. Zhang, N. Liu and X. Zhong: CN102763671-A (2012).

4) K. Moriie and M. Iigatani: JP2002179506-A (2002).

5) L. S. Sandell and R. D. Wysong: WO9508265-A (1995).

6) C. Q. Sun, Y. J. Wang, C. H. Zhang and Z. J. Zhang: Pestic Sci. Admin. 34, 14-17 (2013) (in Chinese).

7) L. Liu, Y. X. Pang, X. P. OuYang, X. N. Li and X. Q. Qiu: Agrochemicals 50, 720-723 (2011) (in Chinese).

8) S. S. Kamath and M. R. Sawant: J. Dispersion Sci. Technol. 29, 535541 (2008).

9) G. A. Bell: Pestic. Sci. 29, 467-473 (1990).

10) H. T. Delli Colli and I. W. Doering: "Pesticide Formulations and Application Systems," Vol. 12, ed. by A. K. Viets, R. S. Tann and J. C. Mueninghoff, ASTM International, West Conshohocken, PA, pp.
141-151, 2001.

11) Y. Jiao, Y.-P. Lu, G.-Y. Xiao, W.-H. Xu and R.-F. Zhu: Powder Technol. 217, 581-584 (2012).

12) D. P. Mondal, M. Patel, S. Das, A. K. Jha, H. Jain, G. Gupta and S. B. Arya: Mater. Des. 63, 89-99 (2014).

13) J. Čapek and D. Vojtěch: Mater. Sci. Eng. C 43, 494-501 (2014).

14) L. Wang, J. Zhang, L. Xu and Y. Qian: Mater. Res. Bull. 46, 1703-1707 (2011).

15) M. Nojiri, H. Hasegawa, T. Ono, T. Kakui, M. Tsukada and H. Kamiya: J. Ceram. Soc. Jpn. 111, 327-332 (2003).

16) J. G. Reynolds, P. R. Coronado and L. W. Hrubesh: J. Non-Cryst. Solids 292, 127-137 (2001).

17) C. Galle: Cement Concr. Res. 31, 1467-1477 (2001).

18) E. W. Washburn: Phys. Rev. 17, 374-375 (1921).

19) L. Korat, V. Ducman, A. Legat and B. Mirtic: Ceram. Int. 39, 69977005 (2013).

20) D. Snoeck, L. F. Velasco, A. Mignona, S. Van Vlierberghe, P. Dubruel, P. Lodewyckx and N. De Belie: Cement Concr. Res. 64, 54-62 (2014). 